\title{
Organizational and technical factors of urban territories redevelopment
}

\author{
Dmitry Topchiy* , Lapidus Azariy \\ Moscow State University of Civil Engineering, 129377, Moscow, Russia
}

\begin{abstract}
The dynamism of changes in the external environment of residential real estate objects with the simultaneous limitation of urban areas are the main prerequisite for creating new construction projects that have a high level of investment attractiveness. Such combined factors open up and increase the importance of using such a tool as redevelopment. Residential formations (complexes, districts, blocks, individual objects) are an obvious result of the artificial organization of the territory urban environment available for development. The quality of the organization of an artificial (residential) environment is determined primarily by the level of technical and moral condition of capital construction objects of residential purposes: houses, buildings, complexes, districts (microdistricts). The considered structural objects of the urban environment are exposed in the course of their functioning (operation) to certain natural and climatic, technical and technological, and social and cultural influences that lead to a certain loss of the original (established) quality of construction products. This loss of quality is expressed in the partial or complete loss of the ability of a construction object (complex of objects) to provide a comfortable and safe life for groups of the population or individuals living in the territory under consideration. Many industrial enterprises, especially old ones, are therefore unable to withstand competition and the economic component of their existence, and are not able to provide an appropriate environmental environment. In this regard, the most rational and mutually beneficial solution is considered to be the transfer of such enterprises outside the city borders, or to specially designated industrial areas, with the subsequent redevelopment of the liberated territory for the needs of the city itself, housing construction, or social and cultural or business facilities. City municipalities are also interested in this process in order to revitalize large areas that are often empty or under-used. The economic component of this process for the city, with proper redevelopment will be tax increases that will be transferred to the city from the well-functioning of the new building complex, providing the population of the city and its district the most popular services. It is particularly necessary to highlight industrial urban areas that have historical significance and contain objects of high architectural value on their territories, which give special expressiveness to the appearance of cities. In addition to social, economic, and environmental issues, the issue
\end{abstract}

\footnotetext{
${ }^{*}$ Corresponding author: dvtopchiy0405@gmail.com
} 
of redevelopment of all these territories also has a certain historical significance, including from the point of view of preserving not only the architectural features, but also the special microclimate of each particular urban district. The paper presents the results of a study of the problem of improving the efficiency of the organization of works on the redevelopment of urban territories in the conditions of existing development.

\section{Introduction}

Redevelopment is aimed at physical placement and regulation of land use and structure. However, reconstruction goals should also include other aspects of community development, such as design, preservation of historical assets, public spaces, environmental components, environmental restoration, and even issues that increase the level of social services provided to residents of the surrounding area [1].

It is particularly necessary to highlight industrial urban territories that have historical significance and contain objects of high architectural value on their territories, which give special expressiveness to the appearance of cities [2]. In addition to social, economic, and environmental issues, the issue of redevelopment of such territories also has a certain historical significance, including from the point of view of preserving not only the architectural features, but also the special microclimate of each specific urban district.

Complex redevelopment usually refers to areas that are released after production has been withdrawn and often require the creation of an entire area with all the necessary infrastructure. Industrial areas and blocks that have lost their production function should be adapted to the modern urban environment, changing their original purpose. Redevelopment, from an economic point of view, can be defined as the transformation of a real estate object in order to use it more efficiently. As a result of redevelopment, a product (real estate) with a higher market value should be produced by attracting investment resources. From the point of view of the State, redevelopment can be defined as a process that ultimately increases the value and liquidity of the land plot and real estate objects located on it, due to competent changes in the functional purpose, construction of new and / or reconstruction of old buildings. Taking into account the Urban Development Code of the Russian Federation, the main goals of redevelopment are to achieve a balance of social, economic, environmental and institutional components of territorial development.

One of the most controversial issues of redevelopment is the optimal direction of redevelopment, which should take into account a complex of issues of urban planning, functional, social, organizational, technical, economic and environmental nature, and in the case of a historical place or territory, as well as the need, possibility and feasibility of preserving the architectural appearance, referred to in the work - a unique industrial environment. The unique industrial environment is carefully studied by urban planners, historians, architects, cultural scientists, developers and investors.

\section{Literature Review}

A significant contribution to the creation and improvement of production organization methodologies was made by: Volkov A. A., Gusakov A. A., Lapidus A. A., Monfred Y.B., Oleynik P. P., Kievsky L. V., Ilyin N. I., Prykin B. V., Telichenko V. I., Chulkov V. O., Schreiber A. K., Bulgakov S. N., Sinenko S. A., Gusakova E. A. and others.

The range of issues that have to be solved within the framework of this problem requires in-depth theoretical and experimental research. There are a lot of works in this 
direction, especially by foreign scientists, but there are practically no works by Russian scientists on evaluating and improving the efficiency of urban territories redevelopment in the conditions of the current development [3]. In this regard, it is necessary to conduct research on the processes of redevelopment of industrial territories in the conditions of current development and their effectiveness [4].

The principles and methods of organizing redevelopment processes in the context of increasing the potential of the urban environment are considered in the works of foreign scientists, such as: Aarikka-Stenroos L., Adair A., Alevantis L., Alvesson M., Avlonitis G.J., Bullen P.A., Chase R.B., Chen H., Chia R., Cox F., Daugherty P.J., Davies R., Dimitriadis S., Edvardsson B., Eisenhardt K.M., Ellison L., Ende J., Ferrin B.G., Fothergill S. and others.

\section{Methodology}

The effectiveness of existing methods of organizing works on redevelopment of industrial clusters is manifested in several aspects and includes:

- assessment of the private effect during a certain stage of redevelopment, which can be represented by a synergistic effect or reduction of financial costs;

- assessment of the economic efficiency of a certain stage of the organization of work on redevelopment, which consists in determining the current cost;

- assessment of the parametric component of the organization of work on redevelopment, including the calculation of the cost or expenses of individual indicators in this case;

- assessment of the competitiveness of the completed organization of work on redevelopment, which indicates the feasibility or lack thereof in the end.

To assess the effectiveness of existing methods of organizing work on the redevelopment of industrial clusters, all of the abovementioned can be used, both separately and in the synthesis of estimates.

Redevelopment of industrial territories in the conditions of current development will be considered as a single system consisting of the following main interacting three subsystems:

- organizational and technical solutions;

- organizational structures;

- information environment.

At all stages of the urban cluster redevelopment project, the efficiency of each of the abovementioned subsystems will change and, accordingly, the resulting construction efficiency will change at all stages. At the same time:

- the importance of individual elements of the subsystem of organizational and technical solutions increases, and some decreases; some elements of the subsystem are modified at the stages of the redevelopment project;

- the importance of participants in the subsystem of organizational structures at the stages of the redevelopment project will change;

- the significance of the elements of the information environment subsystem changes at the stages of the construction project, since the type of information transmitted, the form of transmission and control over information also changes.

These subsystems will be characterized by certain parameters, which we denote as:

- $O_{i}^{t r}$ - for organizational and technical solutions, $(i=1,2, \ldots, n)$;

- $O_{j}^{S}$ - for organizational structures, $(j=1,2, \ldots, m)$;

- $I_{k}^{e}$ - for information environment, $(k=1,2, \ldots, p)$.

These parameters will be described below. 
The main stages of construction during the implementation of the industrial cluster redevelopment project are as follows:

- pre-design;

- project development with expertise;

- the stage of construction;

- the stage of commissioning;

- the operational stage;

- the stage of disposal.

In this study, the operation and disposal stages will not be considered.

For clarification, in this paragraph we will understand the macroscopic model of the effectiveness of the stages of the redevelopment project, taking into account the main interacting three subsystems: organizational and technical solutions; organizational structures; the information environment.

Since the main subsystems are 3 in a single system of redevelopment of industrial territories in the conditions of current development, to determine the effectiveness of each of them, we apply a three-dimensional interpretation of their possible values. To describe the performance characteristics of the stages of the project of redevelopment of industrial territories $E_{i j k}^{\Omega}$ in the conditions of current development $\Omega$ and in a certain metric space, and for the set of parameter values of the subsystems under consideration $A_{i j k}^{\Omega}:\left[O_{i}^{t r} ; O_{j}^{S} ; I_{k}^{e}\right]$, we use a geometric parallelepiped in the form $E_{i j k}^{\Omega}:\left[O_{i}^{t r} ; O_{j}^{s} ; I_{k}^{e}\right]$.

At the pre-design stage of construction during implementing project of industrial cluster redevelopment with the existing maximum and minimum value of the efficiency of subsystems: organizational and technical solutions

$$
E_{i}^{\Omega}:\left[O_{\min }^{\operatorname{tr} 1} ; O_{\max }^{\operatorname{tr} 1}\right],
$$

organizational structures

$$
E_{j}^{\Omega}:\left[O_{\min }^{s 1} ; O_{\max }^{s 1}\right]
$$

information environment

$$
E_{k}^{\Omega}:\left[I_{\min }^{e 1} ; I_{\max }^{e 1}\right]
$$

Figure 1 provides an interpretation of the macroscopic model of maximum efficiency at this stage of the project of industrial cluster redevelopment.

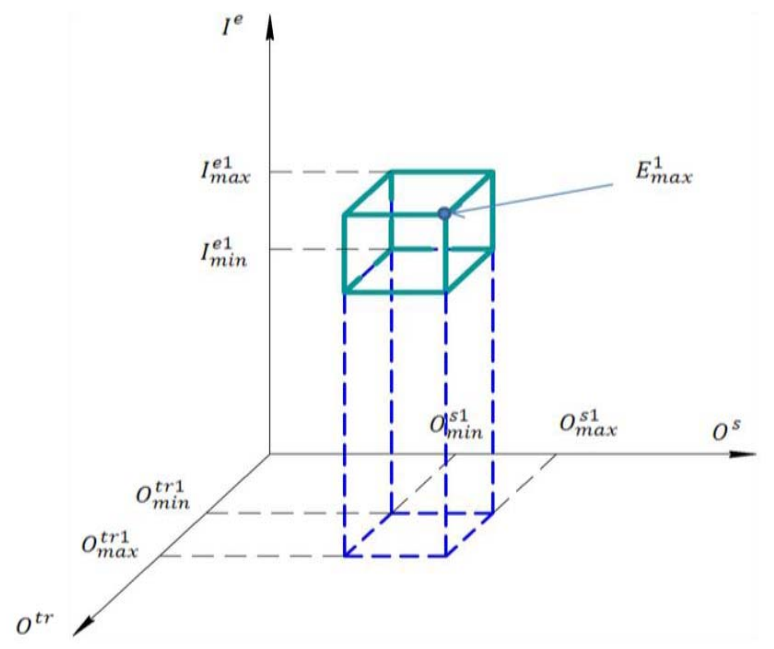


Fig.1. Graphical expression of the efficiency model of the urban territory redevelopment project

Figure 1 shows a fragment of a parallelepiped in bold lines, the nodes of which will be an indicator of efficiency at the pre-design stage of construction when implementing the project of industrial cluster redevelopment. The node with the maximum efficiency of all considered subsystems is shown separately [5].

If we assume that the efficiency of industrial cluster before redevelopment can be described by some specific parameters $E_{0}^{\Omega}:\left[O_{0}^{t r} ; O_{0}^{S} ; I_{0}^{e}\right]$ for the conditions of the existing development $\Omega$, then we can determine the maximum change in the efficiency value using the Euclidean or Manhattan metric [6]. In this case the proximity (minimum) or the range (maximum) of the location of efficiency of industrial cluster on the pre-design stage during implementation of project of industrial cluster redevelopment compared to the initial state will be determined.

For the case of determining with the Euclidean metric, the range (maximum) of the location of the efficiency of industrial cluster at the pre-design stage of construction during the implementation of project of industrial cluster redevelopment compared to the initial state can be determined from the following expression:

$$
\begin{gathered}
E_{\max }^{*}=\max _{\left(E_{\max 1}^{1}, E_{\max 2}^{1}, \ldots, E_{\max \kappa}^{1}\right) \in F r A_{i j k}^{\Omega}} \sqrt{\sum_{i, j, k=1}^{N}\left(E_{0}^{\Omega}-E_{\max i, j, k}^{1}\right)^{2}}, \\
\text { under the condition } E_{0}^{\Omega} \prec E_{\max }^{1} i, j, k
\end{gathered}
$$

where $\operatorname{Fr} A_{i j k}^{\Omega}$ - the border of parallelepiped $A_{i j k}^{\Omega}$.

Finding the maximum by the given expression makes sense only in the case of lower efficiency, i.e. at lower values of the initial efficiency.

For application Manhattan metric, which is determined by the sum of the lengths of the projections of the segment located between the points on the coordinate axis, range (maximum) location of efficiency of industrial cluster at the pre-design stage of construction during the implementation of project of industrial cluster redevelopment compared to the initial state can be determined from the following expression:

$$
\begin{aligned}
& E_{\text {max }}^{*}=\max _{\left(E_{\text {max } 1}^{1}, E_{\text {max }}^{1}, \ldots, E_{\text {max } \mathrm{x}}^{1}\right) \in F r A_{i j k}^{\Omega}} \sum_{i, j, k=1}^{\aleph}\left|E_{0}^{\Omega}-E_{\text {max } i, j, k}^{1}\right|, \\
& \text { under the condition } E_{0}^{\Omega} \prec E_{\max i, j, k}^{1} \text {. }
\end{aligned}
$$

The graphical interpretation of the above expressions is shown in figure 2 . 


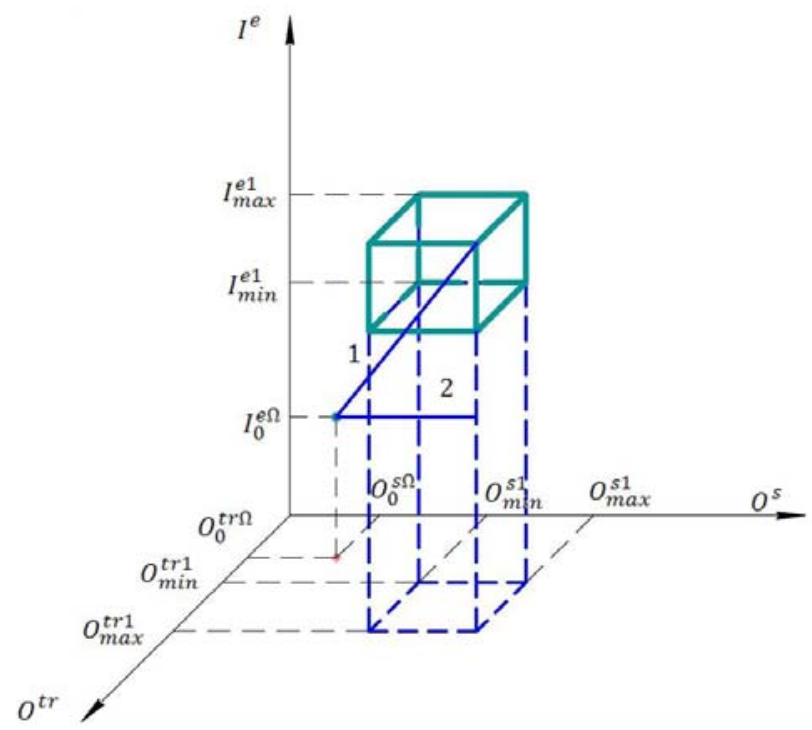

Fig.2. Graphical interpretation of finding the maximum efficiency of industrial cluster at the predesign stage of construction during the implementation of project of industrial cluster redevelopment compared to the initial state $E_{0}^{\Omega}$ for the cases of using Euclidean and Manhattan metrics

However, it should be noted that in the above expressions, the distances should be weighted in accordance with the considered subsystems, i.e. weight coefficients should be added:

- $G_{i}^{t r}$ - for organizational and technical solutions, $(i=1,2, \ldots, n)$;

- $G_{j}^{s}$ - for organizational structures, $(j=1,2, \ldots, m)$;

- $G_{k}^{e}$ - for information environment, $(k=1,2, \ldots, p)$.

Note that the above weight coefficients can be determined from the normative literature, taking into account the weighted average practical results.

In this regard, we write refined expressions taking into account the weight coefficients:

- for the Euclidean metric:

$$
\begin{gathered}
E_{\text {max }}^{*}=\max _{\left(E_{\text {max } 1}^{1}, E_{\text {max } 2, \ldots, E_{\text {max }}^{1} i, j, k}^{1}\right) \in F r A_{i j k}^{\Omega}}\left(\sum_{i=1}^{\mathrm{n}} G_{i}^{\operatorname{tr}}\left(E_{0}^{\Omega}-E_{\text {max } i}^{1}\right)^{2}+\right. \\
\left.+\sum_{j=1}^{\mathrm{m}} G_{j}^{S}\left(E_{0}^{\Omega}-E_{\text {max } j}^{1}\right)^{2}+\sum_{k=1}^{\mathrm{p}} G_{k}^{e}\left(E_{0}^{\Omega}-E_{\text {max } k}^{1}\right)^{2}\right)^{1 / 2}, \\
\text { under the condition } E_{0}^{\Omega} \prec E_{\text {max } i, j, k}^{1} ;
\end{gathered}
$$

- for the Manhattan metric:

$$
\begin{gathered}
E_{\text {max }}^{*}=\max _{\left(E_{\max 1}^{1}, E_{\max 2}^{1}, \ldots, E_{\max }^{1} i, j, k\right) \in F r A_{i j k}^{\Omega}}\left(\sum_{i=1}^{\mathrm{n}} G_{i}^{t r}\left|E_{0}^{\Omega}-E_{\text {max } i}^{1}\right|+\right. \\
\left.+\sum_{j=1}^{\mathrm{m}} G_{j}^{S}\left|E_{0}^{\Omega}-E_{\max j}^{1}\right|+\sum_{k=1}^{\mathrm{p}} G_{k}^{e}\left|E_{0}^{\Omega}-E_{\max k}^{1}\right|\right)^{1 / 2}, \\
\text { under the condition } E_{0}^{\Omega} \prec E_{\text {max } i, j, k}^{1} .
\end{gathered}
$$

Similar expressions and structures to them can be obtained at the stages of project development with expertise and construction during redevelopment of industrial cluster. 
In this regard, we will write down the final expressions for the maximum of location of the efficiency of industrial cluster at the stages of project development with expertise and construction, taking into account the accepted weight coefficients.

At the stage of project development with expertise during redevelopment of industrial cluster, the maximum of the location of efficiency can be found:

- for Euclidean metric:

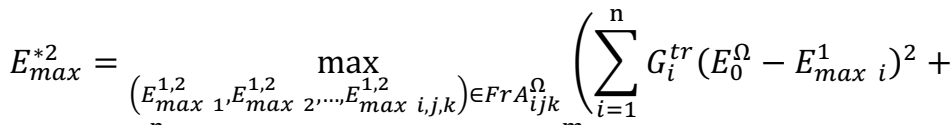

$$
\begin{aligned}
& +\sum_{i=1}^{\mathrm{n}} G_{i}^{\operatorname{tr}}\left(E_{\max i}^{1}-E_{\max i}^{2}\right)^{2}+\sum_{j=1}^{\mathrm{m}} G_{j}^{s}\left(E_{0}^{\Omega}-E_{\max j}^{1}\right)^{2}+ \\
& \sum_{j=1}^{\mathrm{m}} G_{j}^{s}\left(E_{\max j}^{1}-E_{\max j}^{2}\right)^{2}+\sum_{k=1}^{\mathrm{p}} G_{k}^{e}\left(E_{0}^{\Omega}-E_{\max k}^{1}\right)^{2}+ \\
& \left.+\sum_{k=1}^{\mathrm{p}} G_{k}^{e}\left(E_{\max k}^{1}-E_{\max k}^{2}\right)^{2}\right)^{1 / 2} \text {, } \\
& \text { under the condition } E_{0}^{\Omega} \prec E_{\max i, j, k}^{1} \prec E_{\max i, j, k}^{2} \text {; }
\end{aligned}
$$

- for the Manhattan metric:

$$
\begin{aligned}
& E_{\text {max }}^{* 2}=\max _{\left(E_{\max 1}^{1,2}, E_{\max }^{1,2}, \ldots, E_{\max }^{1,2, j, k}\right) \in F r A_{i j k}^{\Omega}}\left(\sum_{i=1}^{\mathrm{n}} G_{i}^{t r}\left|E_{0}^{\Omega}-E_{\text {max } i}^{1}\right|+\right. \\
& +\sum_{i=1}^{\mathrm{n}} G_{i}^{\operatorname{tr}}\left|E_{\text {max } i}^{1}-E_{\text {max } i}^{2}\right|+\sum_{j=1}^{\mathrm{m}} G_{j}^{s}\left|E_{0}^{\Omega}-E_{\text {max } j}^{1}\right|+ \\
& +\sum_{j=1}^{\mathrm{m}} G_{j}^{s}\left|E_{\max j}^{1}-E_{\max j}^{2}\right|+\sum_{k=1}^{\mathrm{p}} G_{k}^{e}\left|E_{0}^{\Omega}-E_{\max k}^{1}\right| \\
& \left.+\sum_{k=1}^{\mathrm{p}} G_{k}^{e}\left|E_{\max k}^{1}-E_{\max k}^{2}\right|\right)^{1 / 2}, \\
& \text { under the condition } E_{0}^{\Omega} \prec E_{\text {max } i, j, k}^{1} \prec E_{\max i, j, k}^{2} \text {. }
\end{aligned}
$$

At the stage of construction during redevelopment of industrial cluster:

- for Euclidean metric:

$$
\begin{aligned}
& E_{\text {max }}^{* 3}=\max _{\left(E_{\max 1}^{1,2,3}, E_{\max 2}^{1,2, \ldots, E_{\max }^{1,2,3} i, j, k}\right) \in F r A_{i j k}^{\Omega}}\left(\sum_{i=1}^{\mathrm{n}} G_{i}^{\operatorname{tr}}\left(E_{0}^{\Omega}-E_{\text {max } i}^{1}\right)^{2}+\right. \\
& +\sum_{i=1}^{\mathrm{n}} G_{i}^{t r}\left(E_{\max i}^{1}-E_{\max i}^{2}\right)^{2}+\sum_{i=1}^{\mathrm{n}} G_{i}^{t r}\left(E_{\text {max } i}^{2}-E_{\text {max } i}^{3}\right)^{2}+ \\
& +\sum_{j=1}^{\mathrm{m}} G_{j}^{s}\left(E_{0}^{\Omega}-E_{\max j}^{1}\right)^{2}+\sum_{j=1}^{\mathrm{m}} G_{j}^{s}\left(E_{\max j}^{1}-E_{\max j}^{2}\right)^{2}+ \\
& +\sum_{j=1}^{\mathrm{m}} G_{j}^{S}\left(E_{\max j}^{2}-E_{\max j}^{3}\right)^{2}+\sum_{k=1}^{\mathrm{p}} G_{k}^{e}\left(E_{0}^{\Omega}-E_{\max k}^{1}\right)^{2}+ \\
& \left.+\sum_{k=1}^{\mathrm{p}} G_{k}^{e}\left(E_{\max k}^{1}-E_{\max k}^{2}\right)^{2}+\sum_{k=1}^{\mathrm{p}} G_{k}^{e}\left(E_{\max k}^{2}-E_{\max k}^{3}\right)^{2}\right)^{1 / 2} \text {, } \\
& \text { under the condition } E_{0}^{\Omega} \prec E_{\max i, j, k}^{1} \prec E_{\max i, j, k}^{2} \prec E_{\max i, j, k}^{3} \text {; }
\end{aligned}
$$


- for the Manhattan metric:

$$
\begin{aligned}
& E_{\text {max }}^{* 3}=\max _{\left(E_{\max 1}^{1,2,3}, E_{\max }^{1,2,3, \ldots, E_{\max }^{1,2,3, j, k}}\right) \in F r A_{i j k}^{\Omega}}\left(\sum_{i=1}^{\mathrm{n}} G_{i}^{t r}\left|E_{0}^{\Omega}-E_{\max i}^{1}\right|+\right. \\
& +\sum_{i=1}^{\mathrm{n}} G_{i}^{t r}\left|E_{\max i}^{1}-E_{\max i}^{2}\right|+\sum_{i=1}^{\mathrm{n}} G_{i}^{t r}\left|E_{\max i}^{2}-E_{\text {max } i}^{3}\right|+\sum_{j=1}^{\mathrm{m}} G_{j}^{s}\left|E_{0}^{\Omega}-E_{\text {max } j}^{1}\right|+ \\
& +\sum_{j=1}^{\mathrm{m}} G_{j}^{S}\left|E_{\text {max } j}^{1}-E_{\text {max } j}^{2}\right|+\sum_{j=1}^{\mathrm{m}} G_{j}^{S}\left|E_{\max j}^{2}-E_{\text {max } j}^{3}\right|+\sum_{k=1}^{\mathrm{p}} G_{k}^{e}\left|E_{0}^{\Omega}-E_{\text {max } k}^{1}\right|+ \\
& \left.+\sum_{k=1}^{\mathrm{p}} G_{k}^{e}\left|E_{\max k}^{1}-E_{\max k}^{2}\right|+\sum_{k=1}^{\mathrm{p}} G_{k}^{e}\left|E_{\max k}^{2}-E_{\max k}^{3}\right|\right)^{1 / 2}, \\
& \text { under the condition } E_{0}^{\Omega} \prec E_{\max i, j, k}^{1} \prec E_{\max i, j, k}^{2} \prec E_{\max i, j, k}^{3} \text {. }
\end{aligned}
$$

Finding the maxima using the above expressions also makes sense only in the case of lower efficiency, i.e. with lower values of the initial efficiency for the case of an optimistic forecast under the condition:

$$
E_{0}^{\Omega} \prec E_{\max i, j, k}^{1} \prec E_{\max i, j, k}^{2} \prec E_{\max i, j, k}^{3} .
$$

\section{Results}

As a result, figure 3 shows the final interpretation of the macroscopic model of maximum efficiency at the considered stages of the project of industrial cluster redevelopment based on the given expressions - at the stage of project development with expertise and at the final stage of construction.

From the given graphical interpretation (figure 3), in the case of an optimistic forecast of the implementation of the construction stages of the project of redevelopment of industrial cluster, we see that the efficiency in accordance with the macroscopic model increases at each stage, even the minimum value of efficiency. However, in practice, if the parameters of one of the subsystems of organizational and technical solutions, organizational structures, or information environment at a certain stage of construction during the implementation of a project of redevelopment of industrial cluster are less than the minimum values, then we can expect pessimistic results of construction efficiency.

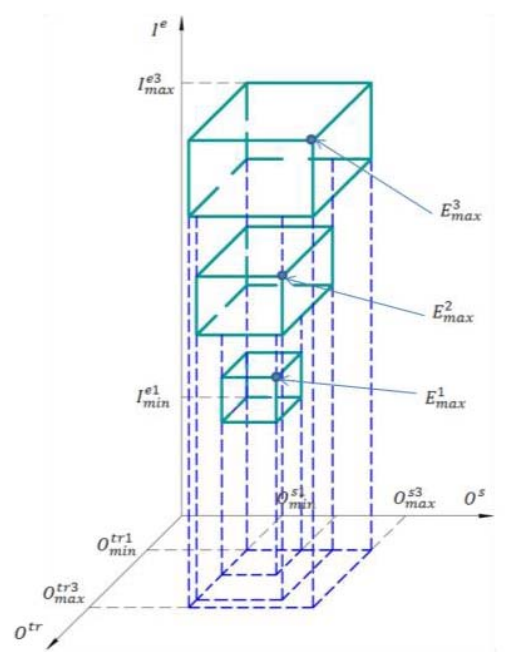


Fig.3. Interpretation of the macroscopic model of maximum efficiency at the considered construction stages during implementation of the project of redevelopment of industrial cluster

In this case, the parallelepipeds may eventually coincide or have a different tendency to change efficiency in accordance with the macroscopic model at each stage of the project of redevelopment of industrial cluster.

\section{Discussion}

The previously mentioned subsystems of the unified system of industrial territories redevelopment in the conditions of current development are characterized by certain parameters

$$
O_{i}^{t r}, O_{j}^{s}, I_{k}^{e}
$$

In addition, the number of parameters of this subsystem can be increased to the required value $O_{n}^{\text {tr }}$, if a decision is made about the importance of additional parameters that affect the effectiveness of the subsystem of organizational and technical solutions during redevelopment of industrial territories in the conditions of current development.

Also, the number of parameters of the subsystem of organizational structures can be increased to the required value $O_{m}^{s}$, if a decision is made about the importance of additional parameters that affect the effectiveness of this subsystem during redevelopment of industrial territories in the conditions of current development.

In this case, we note that the number of parameters of the information environment subsystem can be increased to the required value $I_{p}^{e}$, if a decision is made about the importance of additional parameters that affect the effectiveness of this subsystem during redevelopment of industrial territories in the conditions of current development.

Each subsystem has its own maximum, weighted average, and minimum values at the stage of pre-design works during the redevelopment of industrial cluster. The final efficiency of the project, which is shown in figure 5.5, according to the microscopic model is characterized by the same values.

In accordance with the constructed model and a clear example at the stage of pre-design works, it follows that in the theoretical and practical aspect, the most acceptable value for the efficiency of the project of industrial cluster redevelopment will be its maximum value, which should be sought. In practice, in reality, the best option is the weighted average value of the efficiency of the project of industrial cluster redevelopment.

Also, it should be noted that the minimum values of the efficiency of the project of industrial cluster redevelopment will be a marker of risks that may arise at the pre-design stage (as well as at other stages of the project of redevelopment). At the same time, the minimum risk will be determined by the difference between the maximum and minimum values of the efficiency of the project of industrial cluster redevelopment.

Minimum values for the efficiency of the project of industrial cluster redevelopment can be associated with the maximum number of risks during the implementation of the project as a whole or at a certain stage.

In addition, the indicator of inefficiency of the project of industrial cluster redevelopment will be the minimum efficiency values found for each subsystem and at each stage of the implementation of construction project.

The weighted average value of the efficiency of the project of industrial cluster redevelopment at each stage of the implementation of construction project should be attributed to the optimal values, which will ensure minimal risks, without unnecessary financial, time and other costs, and ensure the stability of interaction of all subsystems of the unified project system. 
When developing a synergistic model for the evolution of cluster redevelopment in an urban environment, the ensembles (principles) will be subsystems:

- organizational and technical solutions $-\varepsilon_{11}$;

- organizational structures $-\varepsilon_{22}$;

- information environment $-\varepsilon_{33}$.

The double index for designating ensembles is used for convenience, since various principles are combined: engineering and technical, environmental and aesthetic, volumetric and planning.

In turn, the ensembles of the synergetic model for the evolution of industrial cluster redevelopment in urban environment include individual elements designated as $x_{i j}$, which correspond to the parameters of subsystems previously given in the chapter.

It should be noted that the number of individual elements in the ensemble of the synergetic model for the evolution of cluster redevelopment in an urban environment may vary.

To implement a synergistic model for the evolution of redevelopment, we can use a software method using computer technologies.

Based on the above, we will analyze the transformation of the cluster's structural elements when interacting with the urban environment.

Let's assume that the ensemble $\varepsilon_{i j}$ containing $i$ elements of the same type has a composition with $j$ separate elements of cluster redevelopment, and the kinetics of transformation processes can be described by some stochastic differential equation:

$$
\frac{d x_{j}^{i}}{d t}=f_{i j}\left(x_{1}^{i}, x_{2}^{i}, \ldots, x_{n}^{i}\right)-g_{i j}\left(x_{1}^{i}, x_{2}^{i}, \ldots, x_{n}^{i}\right),
$$

where $j$-is the corresponding energy state; $j=1, \bar{n} ; i=1, \bar{m}$;

$x_{1}^{i}, x_{2}^{i}, \ldots, x_{n}^{i}$ - are instantaneous values of the internal stored energy $j$, with the function $f_{i j}$, which is the rate of increase of this energy, and the function $g_{i j}$, which is the energy dissipation.

The structural element of industrial cluster redevelopment, which is located in a certain ensemble $\varepsilon_{i}(i j=1, \bar{m})$ under conditions of an urban environment, tries to achieve dynamic constancy of the stationary state:

i.e.:

$$
M\left[\frac{d x_{j}^{i}}{d t}\right]=0, j=1,2, \ldots, n^{e}
$$

$$
M\left[f_{i j}\left(x_{1}^{i}, x_{2}^{i}, \ldots, x_{n}^{i}\right)\right]=M\left[g_{i j}\left(x_{1}^{i}, x_{2}^{i}, \ldots, x_{n}^{i}\right)\right]=M\left[y_{i j}^{k}\right]
$$

The random variable $y_{i j}^{k}$ is characterized by intensive functioning of the $k$-th element $(k=1, \vec{l})$, which refers to the ensemble of cluster redevelopment $\varepsilon_{i}(i=1, \bar{n})$.

The influence of each structural element of cluster redevelopment increases, and the $k$ th element under conditions of urban environment is at a time interval $\left(t_{0}-t\right)$, so there is a fair inequality:

$$
M\left[y_{i j}^{k}\right]_{t} \geq M\left[y_{i j}^{k}\right]_{t 0^{\prime}}
$$

this only leads to uneven and unstable functioning under the conditions of urban environment

$$
D\left[y_{i j}^{k}\right]_{t} \geq D\left[y_{i j}^{k}\right]_{t 0}
$$


On the other hand, it can be argued that with an increase in the unstable functioning and duration of the structural element of industrial cluster redevelopment, the probability function of the occurrence of structural elements that are part of the ensemble $\varepsilon_{i}(i=1, \bar{n})$ of cluster redevelopment under the conditions of urban environment will look like:

$$
P_{\varepsilon t}(t)=\exp \left(-k_{e} \int_{t 0}^{t} D\left[y_{i j}^{k}\right] d t\right),
$$

and reflect the probability of occurrence of the structural $k$-th element from the ensemble $\varepsilon_{i}$ from the time of formation $t_{0}$ to the corresponding time $t$.

If we denote:

$$
Z^{i}=\sum_{k=1}^{i} y_{i j}^{k}
$$

then we can write:

$$
P_{\varepsilon t}(t)=\exp \left(-k_{e} \int_{t 0}^{t} D\left[Z^{i}\right] d t\right) .
$$

When forming ensembles of elements for industrial cluster redevelopment under the conditions of urban environment, the rule of superadditivity is obeyed, i.e.:

$$
P_{\varepsilon t}(t) \geq P_{\varepsilon(i-j)}(t)+P_{\varepsilon j}(t),
$$

if $t \geq t_{0}$ i $t_{0}$ - sufficiently large time constant and not equal to zero (operation under the conditions of urban environment).

From the above expressions, we can state the following: if the formation of ensembles (principles) of elements of cluster redevelopment under the conditions of urban environment obeys the rule of superadditivity, then the reorganization of their ensemble structures is the basis for the end of the process of organization (or self-organization) of these structures.

If these conditions are met and integer functions of this type are introduced:

$$
V(t)=\left[v_{1}(t), v_{2}(t), \ldots, v_{i}(t)\right]
$$

where $v_{i}(t)$ represents the same ensembles of cluster redevelopment $\varepsilon_{i}$ for a suitable time point $t$, then the expression can be rewritten as follows:

$$
P_{\varepsilon t}(t)=\exp \left(-k_{e} \int_{t 0}^{t} D\left[\sum_{i=1}^{m} v_{i} Z^{i}\right] d t\right) .
$$

This expression characterizes the level of completion of the cluster construction process under the conditions of urban environment.

At the same time, it is necessary to take into account that the activity of a particular ensemble $\varepsilon_{i}$, which is located in a group of the same ensembles, is characterized by a statically equivalent average value for all industrial clusters.

Structural elements of cluster redevelopment always try to come to an organization with the maximum probability function of their occurrence (self-organization), provided that energy is constantly absorbed and dissipated at a given level under the conditions of urban environment at:

$$
M\left[\sum_{i=1}^{m} v_{i}(t) Z^{i}(t)\right]
$$


or

$$
V^{*}(t)=\left[v_{1}^{*}(t), v_{2}^{*}(t), \ldots, v_{m}^{*}(t)\right]
$$

$$
P^{*}(t)=\left[P_{1}^{*}(t), P_{2}^{*}(t), \ldots, P_{m}^{*}(t)\right]
$$

and is completely suitable for the specific conditions of the urban environment for which $\rho \in S$.

The condition for the maximum occurrence of structural elements of cluster redevelopment with balanced instability of their functioning under the conditions of urban environment is as follows:

$$
W(v)=D\left[\sum_{i=1}^{m} v_{i}(t) Z^{i}(t)\right] \rightarrow \min ,
$$

with a convex function that tends to the minimum value.

Using the provisions of work [42], we can write the following relation:

$$
W(v)=\sum_{i=1}^{m} v_{i}^{2} D\left[Z^{i}(t)\right] .
$$

The functional $W(v)$ is a convex function of the inherent affiliation of the optimal plan $V^{*}=\left[v_{1}{ }^{*}, v_{2}{ }^{*}, \ldots, v_{m}{ }^{*}\right]$ with the minimization of the functional.

When structural entropy is taken into account:

$$
S_{c}=-\sum_{i=1}^{m} P_{\alpha i} \ln P_{\alpha i},
$$

where $P_{\alpha i}(t)=\frac{v_{i}(t)}{\sum_{i=1}^{n} v_{i}(t)}$ - probability of unbalanced state of structural elements of cluster redevelopment under the conditions of urban environment;

the expression implies the following: each condition of the urban environment $s_{1} \in S$ is characterized by the state of optimal organization of ensembles of elements of cluster redevelopment with structural entropy $S_{c}\left(P_{1}^{*}\right)$, which tries to maximize the probability function of the occurrence of structural elements.

Also, each change of the urban environment conditions $s_{2} \in S$ is characterized by a new state of optimal organization of the probabilities of cluster redevelopment ensembles with structural entropy $S_{c}\left(P_{2}^{*}\right)$. When setting a new state of the organization $S_{e}\left(P_{2}^{*}\right)$ in the new conditions of the urban environment, the spatial distribution of local conditions of this environment changes to the structural elements with which the corresponding ensembles of cluster redevelopment are in equilibrium.

For the case when $P_{2}^{*} \neq 0(i=1, \bar{m})$, the value of the difference between the stationary state of structural elements from the position of the initial organization of cluster redevelopment under conditions of urban environment can be expressed by the amount of information by Kullback S.

$$
I\left(\frac{P_{1}^{*}}{P_{2}^{*}}\right)=\sum_{i=1}^{m} P_{1 i}^{*} \lg \frac{P_{1 i}^{*}}{P_{2 i}^{*}} .
$$

If the ensemble takes into account the structural elements of the cluster redevelopment, the presence of a sufficient number of elements under the conditions of urban environment we can write the following:

$$
\sum_{j=1}^{m} v_{1}^{*} j \approx \sum_{k=1}^{m} v_{2}^{*} k
$$

then we write the relation: 


$$
\frac{P_{1 i}^{*}}{P_{2 i}^{*}} \approx \frac{P_{1 i}^{*} \sum_{j=1}^{m} v_{1 j} M\left[Z^{j}\right]}{P_{2 i}^{*} \sum_{j=1}^{m} v_{2 k} M\left[Z^{k}\right]}
$$

which represents the ratio of individual particles of ensembles $\varepsilon_{i}$ of industrial cluster redevelopment before and after changes in urban environment conditions.

Changes in urban environment conditions are characterized by disorganization of industrial cluster redevelopment ensembles with subsequent organization of new structural elements. The value of disorganization of industrial cluster redevelopment ensembles is characterized by the proportionality of the measure of differences in these changes in urban environment conditions, which can be expressed by S. Kullback information.

When changing the conditions of the urban environment, the adaptation of industrial cluster redevelopment ensembles to the new conditions $s_{2} \in S$ occurs when the structural elements are disorganized, and their entropy reaches values of:

$$
S_{0}\left(P_{1}^{*}, P_{2}^{*}\right)=H\left(P_{1}^{*}\right)+k I\left(\frac{P_{1}^{*}}{P_{2}^{*}}\right),
$$

where $k$ - is some introduced proportionality coefficient.

Next, the structural elements of the industrial cluster redevelopment ensembles are adapted with a new organization of ensemble probabilities $\varepsilon_{i}$, which must correspond to the new conditions of the urban environment $s_{2} \in S$ when applying the principle of maximum probability of structures occurrence.

For the case when $k=1$, the value $S_{c}\left(P_{1}^{*}, P_{2}^{*}\right)$ corresponds to the structural entropy:

$$
S_{0}\left(P_{1}^{*}, P_{2}^{*}\right)=\sum_{i=1}^{m} P_{1 i}^{*} \lg P_{2 i}^{*}
$$

and provides "useful" information about possible structural changes in the structural elements of industrial cluster redevelopment ensembles under conditions of urban environment.

\section{Conclusions}

When implementing the redevelopment of industrial cluster, self-organizing dissipative processes are activated in their elements, as a result of which, under the influence of the urban environment, ordered structures appear. The entropy resulting from interaction with the urban environment is continuously "pumped out" from the structural elements of the industrial cluster redevelopment [7].

To achieve the structural elements of industrial cluster redevelopment of a dynamic stationary state in an urban environment, the following condition must be met [8]:

$$
\sigma[S] \rightarrow 0 .
$$

The organization of structural elements of industrial cluster redevelopment in the urban environment from the position of synergetic is the distribution of ensembles of elements that consist of a corresponding number of factors, each of which performs the solution of certain local tasks [9]. In case of random changes of the local urban environment conditions, the probabilistic part of the structural elements in the respective ensembles is determined, each of which is in equilibrium with the urban environment and is the subject of multi-channel regulation, contains a certain number of simultaneously operating structural elements of redevelopment of industrial cluster [10]. 
The purpose of functioning is to maximize the function of individual structural elements of industrial cluster redevelopment under the conditions of urban environment [11].

\section{References}

1. S.K. Brown, "High quality indoor environments for office buildings", Proceedings of 2nd International Conference of the CRC for Construction Innovation, 12-14 March, CRC Press, Boca Raton, FL. (2006)

2. A. Shah, and A. Kumar, "Challenges in residual service life assessment for refurbishment projects", Proceedings of the 11th Pacific Rim Real Estate Society Conference, PRRES 2005, Melbourne, (2005)

3. European Union "A sustainable Europe for a better world: European Union strategy for sustainable development”, (2001) http://europa-eu.int/eur-lex/eu/com/cn/2001/ $\operatorname{com} 2001$

4. P.P. Oleynik, Organization of construction production (Monograph, Publishing house $\mathrm{ACB}, 2010)$

5. E.A. Kremcheev, D.S. Gromyka, \& D.O. Nagornov, Techniques to determine spontaneous ignition of brown coal, Journal of Physics: Conference Series, (2018)

6. L.P. Lingaitis, S. Mjamlin, D. Baranovsky, V. Jastremskas, Prediction methodology of durability of locomotives diesel engines, Eksploatacja i Niezawodnosc - Maintenance and Reliability 14 (2) 154-159 (2012)

7. D. Kremcheeva, \& E. Kremcheev, Use of a quality management system at the iron and steel enterprise, Journal of Mechanical Engineering Research and Developments 41(1), 151-155 (2018)

8. P.S. Lufkin, A. Desai, and J. Janke, Estimating the restoration and modernization costs of infrastructure and facilities, Public Works Management and Policy 10, 40-52 (2005)

9. I.I. Sytko, \& D.A. Kremcheeva, Instrumentation for measuring the parameters and characteristics of four-poles, International Journal of Mechanical Engineering and Technology 8(10), 844-854 (2017)

10. E.A. Kremcheev, D.S. Gromyka, \&, D.O. Nagornov, Techniques to determine spontaneous ignition of brown coal, Journal of Physics: Conference Series, (2018)

11. A. Lievens, and R.K. Moenaert, New service teams as information-processing systems reducing innovative uncertainty, Journal of Service Research 3(1), 46-65 (2000) 